\title{
Da construção da nova capital mineira ao atual modelo de gestão de vilas e favelas: notas sobre um estudo de caso do Programa Vila Viva ${ }^{1}$
}

\author{
Luana Dias Motta*
}

\begin{abstract}
Resumo
A cidade de Belo Horizonte foi planejada para ser modelo de limpeza e símbolo da modernidade e do progresso. Todavia, devido à lógica excludente de seu projeto - fortemente marcado pelos ideais positivistas - teve de se haver com as questões das favelas mesmo antes de sua inauguração. Assim, a história das lutas faveladas e das políticas públicas para essa parcela da população tiveram, desde o período da construção da cidade até os dias atuais, momentos distintos, diretamente relacionados ao contexto histórico local e nacional. Para consolidar, ao longo da década de 1990, uma concepção de planejamento apoiado num discurso universal e técnico - o chamado planejamento modernista (MARICATO, 2000) -, o poder público municipal utilizou (e utiliza) determinadas estratégias legais, políticas e discursivas, que tiveram como principais resultados o Plano Global Específico (PGE) e o Programa Vila Viva. O objetivo central deste texto, portanto, é, a partir de um estudo de caso, refletir sobre o processo de construção e gestão do espaço de Belo Horizonte (que culminou numa cidade espacialmente desigual e excludente), bem como apresentar o percurso metodológico para realização dessa investigação.
\end{abstract}

Palavras-chave: Planejamento urbano; Políticas públicas para favelas; Lutas faveladas; Programa Vila Viva.

A cidade de Belo Horizonte foi planejada para ser modelo de limpeza e símbolo da modernidade e do progresso. Todavia, devido à lógica excludente de seu projeto, fortemente marcado pelos ideais positivistas, teve de se haver com as questões das favelas desde antes de sua inauguração até os dias atuais. Ao longo da história da capital mineira, as lutas faveladas tiveram momentos distintos, relacionados com o momento político do país e com o caráter das políticas públicas locais. A década de 1990 representa um marco na forma de intervir em vilas e favelas em Belo Horizonte. A

\footnotetext{
${ }^{1}$ Este artigo baseia-se na pesquisa empírica e nas reflexões desenvolvidas no âmbito do trabalho de elaboração da minha monografia (Motta, 2009), requisito para conclusão do curso de graduação em Ciências Sociais da UFMG, orientada pela Professora Andréa Zhouri. A pesquisa de campo foi realizada no período em que eu era bolsista de Iniciação Científica da FAPEMIG, vinculada à pesquisa "Mapa dos Conflitos Ambientais do Estado de Minas Gerais", desenvolvida pelo Grupo de Estudos em Temáticas Ambientais GESTA/UFMG.

* Mestranda em Sociologia pela Universidade Federal de Minas Gerais (UFMG) e Bolsista CAPES. Integrante do Grupo de Estudos em Temáticas Ambientais GESTA/UFMG.
} 
partir de 1993, começa a se consolidar em Belo Horizonte um modelo de planejamento urbano que prevê intervenções de tipo estrutural, com a pretensão de superar a fase de intervenções isoladas e pontuais em vilas e favelas. ${ }^{2}$ Nessa perspectiva, a Prefeitura criou, no fim da década de 1990, o PGE, uma espécie de Plano Diretor de cada favela, para possibilitar a superação da fase de intervenções pontuais.

É nessa lógica que, no ano 2005, a Prefeitura Municipal de Belo Horizonte faz suas primeiras intervenções estruturais no Aglomerado da Serra, apresentando o Programa Vila Viva, Intervenção Estrutural em Assentamentos Precários como uma solução inovadora e moderna para os problemas das vilas e favelas da cidade. Financiado pelo Banco Interamericano de Desenvolvimento - BID, pelo Banco Nacional do Desenvolvimento Econômico e Social - BNDES, pela Caixa Econômica Federal, pelo Governo Federal, pela Prefeitura de Belo Horizonte e, recentemente, por verbas do Programa de Aceleração do Crescimento - PAC - (PEREIRA, 2007), o Programa Vila Viva consiste em um conjunto de ações integradas, direcionadas à urbanização, desenvolvimento social e regularização fundiária de vilas e favelas de Belo Horizonte, visando a promoção de profundas transformações dos núcleos habitacionais onde é implementado (BRANDENBERGER, 2002).

As intervenções guiadas por essa concepção de cidade são, muitas vezes, distintas das formas de vida dos moradores das favelas, transformadas de acordo com os objetivos do Programa. As obras relacionadas ao sistema viário, por exemplo, implicam no alargamento de vias já existentes (becos são transformados em ruas e avenidas) e abertura de vias (criação de ruas e avenidas); alterações semelhantes acontecem em decorrência das intervenções de saneamento básico (canalização de esgoto, construção de redes coletoras e de abastecimento de água), que, devido ao cercamento de córregos e à destruição de algumas "pontes”, implicam no fechamento de alguns acessos; obras de criação de parques (locais destinadas à preservação ou utilização coletiva) também isolam áreas antes utilizadas para passagem, lazer ou alguma atividade econômica (hortas, plantas medicinais). As intervenções também implicam, muitas vezes, na retirada/transferência de comércios e outros pontos de referência, como a quadra, o campinho de futebol, a igreja etc.

\footnotetext{
${ }^{2}$ Esse modelo de intervenções estruturais não é exclusivo de Belo Horizonte, ao contrário, está inserido em um contexto nacional de modificação da abordagem das questões de planejamento, especialmente nas favelas. No Rio de Janeiro, por exemplo, começa a se delinear, no final da década de 1980, uma política de intervenções em favelas que culminaria, em 1993, no Programa Favela bairro, que consistia na “ realização de obras de urbanização e na prestação de serviços sociais, assim como de iniciativas preliminares de regularização urbanística e fundiária." (BURGOS, 1998, p. 51).
} 
A pesquisa de campo realizada em dois Aglomerados de Belo Horizonte, onde houve intervenções do Vila Viva, revelam a pretensão do poder público de concretizar o espaço abstrato (dos mapas, planos e projeto) em detrimento do espaço vivido (LEFEBVRE, 1999), com o objetivo de controlar, homogeneizar e enquadrar os espaços e a população da favela. Esse objetivo fica ainda mais evidente com a análise da maneira como os técnicos implementam o Programa Vila Viva no Morro das Pedras (em especial no que se refere ao Projeto Pré-Morar, que prepara as famílias que serão removidas para o uso "adequado" dos apartamentos nos quais serão reassentadas, devido à realização de obras de urbanização) e a partir de entrevistas com moradores removidos de suas casas, no Aglomerado da Serra.

\section{Lutas faveladas e políticas públicas para favelas em Belo Horizonte: da construção da nova capital à Assembleia Nacional Constituinte}

A cidade de Belo Horizonte foi planejada para abrigar o novo centro administrativo do estado de Minas Gerais, consubstanciando o moderno e o progresso em contraposição ao antigo e ao tradicional, marca da então capital Ouro Preto (GUIMARÃES, 1993). O projeto priorizava os aspectos técnicos e de infraestrutura, como acessos (circulação), abastecimento de água, eletricidade e esgotamento sanitário (GUIMARÃES, 1993). O engenheiro responsável pelo projeto, Aarão Reis, acreditava que a ciência poderia fornecer os elementos necessários para a construção de uma cidade moderna, organizada e com funções definidas e localizadas.

No projeto original, a cidade foi dividida em três áreas: urbana, suburbana e rural. A área urbana, delimitada pela Avenida 17 de Dezembro (atual Avenida do Contorno), tinha como características principais rígidas exigências urbanísticas, traçado simetricamente definido e ruas largas para favorecer a circulação - o que mostra a influência de Haussmann, engenheiro que projetou Paris. A área urbana seria, então, destinada aos prédios e espaços públicos e às residências dos funcionários públicos. A outra área, a suburbana, foi pensada para ser uma região residencial de segunda categoria e, por isso, tinha padrões de urbanização mais flexíveis (COSTA, 1994). A área rural ficaria na periferia da cidade e seria uma espécie de "cinturão verde". 
Figura 1 - Planta original de Belo Horizonte projetada por Aarão Reis

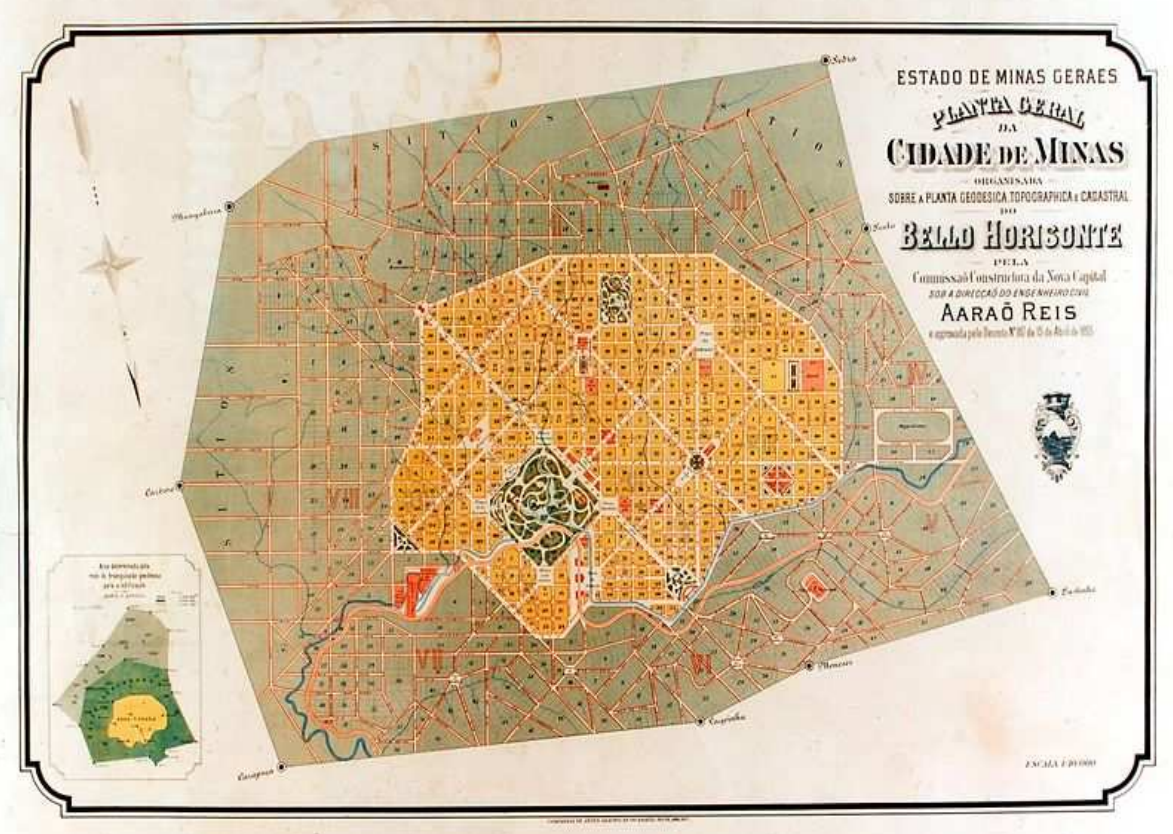

Fonte: (FICHEIRO..., 2012).

Le Ven (1977) crítica o caráter segregacionista do projeto de Aarão Reis, que estabeleceu padrões para os tipos de construção, critérios para a manutenção da higiene e salubridade da cidade, bem como buscou determinar quais espaços poderiam ser ocupados por quais grupos sociais. Essa segregação fica evidente ao observarmos o vazio e a ociosidade criados em alguns espaços da área central (antes, área urbana) que persistem até hoje e, ainda, pela intensa ocupação das áreas rural e suburbana como possibilidade de acesso à moradia na cidade, uma vez que os lotes dentro dos limites da Avenida do Contorno eram muito caros (COSTA, 1994) e os padrões para se construir nessa área eram muito rígidos (AFONSO; AZEVEDO, 1988, p. 113).

Todavia, a ocupação intensa das áreas externas à Avenida do Contorno não significou que a população pobre não ocupava o centro. A construção da cidade necessitou de muita mão de obra, o que atraiu muitos operários, sem que a cidade se preparasse para receber um fluxo tão grande de pessoas. O projeto da nova capital, portanto, não previu o reassentamento dos moradores do Curral Del Rey nem dos operários que vieram para sua construção. Diante das tentativas do poder público de restringir a ocupação da cidade, a população pobre ocupou áreas externas e internas à Avenida do Contorno. Assim, antes mesmo da inauguração, Belo Horizonte já tinha 
duas áreas ocupadas - a do Córrego do Leitão e a do Alto da Estação - que abrigavam três mil pessoas ao todo (GUIMARÃES, 1992). A despeito de ter sido planejada para ser modelo de higiene, limpeza, beleza e modernidade, Belo Horizonte teve de se haver, desde a sua construção, com questões que emergiram da lógica excludente de seu próprio projeto. Já em 1902, na tentativa de controlar e evitar que os operários e pobres ocupassem a área urbana, a Prefeitura cria a Área Operária e realiza as primeiras remoções de favelas na cidade.

Porém, mesmo com a criação e delimitação da Área Operária, as ocupações se espalharam pela cidade, devido ao aumento do número de pessoas pobres vindas do interior do estado. Durante os primeiros 30 anos da capital, o poder público realizou uma série de remoções, o que não colocou fim ao problema, pois as famílias removidas sempre procuravam outras áreas mais desvalorizadas ou nas quais havia necessidade de mão-de-obra. Essa dinâmica viciosa, que destinava à população pobre os espaços mais distantes do centro e dos equipamentos públicos ou aqueles mais próximos do centro e desvalorizados (geralmente por terem uma topografia acidentada), persistiu da época das obras de construção da cidade até o início da década de 1930.

A partir da década de 1930 até os dias de hoje, a organização e as ações dos movimentos sociais e de moradores de favelas de Belo Horizonte, assim como as políticas e ações públicas direcionadas às favelas, estão estreitamente relacionadas ao momento histórico, político e econômico vivido pelo país.

Na primeira metade da década de 1930, por exemplo, as lutas da população periférica se intensificaram, influenciadas pela organização das bases populares da Aliança Libertadora Nacional e também pela criação da Câmara Municipal de Belo Horizonte. Nesse período, o Estado realiza ações no sentido de flexibilizar as exigências para a criação de Áreas Operárias e de controlar a especulação imobiliária e os loteamentos irregulares. (AFONSO; AZEVEDO, 1988). No entanto, a partir de 1937, com a implantação do Estado Novo, a Prefeitura dá início a uma política de erradicação das favelas, passando a tratar a questão como caso de polícia e a vincular a imagem dos favelados à ideia de perigo. São realizadas diversas remoções (mesmo de favelas fora da Avenida do Contorno), justificadas pela necessidade de obras urbanísticas em benefício da coletividade (GUIMARÃES, 1992). Só não foram removidas as favelas nas quais era difícil a realização de obras urbanísticas e aquelas que não interessavam ao mercado imobiliário. Porém, essas remoções não se deram sem resistência; muitas famílias faveladas, ao serem removidas, ocupavam uma nova área, como foi o caso da Barroca, 
que sofreu sucessivas remoções e foi se reconstruindo, diversas vezes, sempre ao longo da Avenida Olegário Maciel.

Mesmo com toda repressão, as políticas e ações para remoção das favelas não conseguiram controlar o crescimento do número de áreas ocupadas, que se intensificou na segunda metade da década de 1940, devido a um quadro que combinava redemocratização, aumento da população e fortalecimento dos movimentos sociais.

Mas é em meados da década de 1950, auge do populismo, que o poder público começa a tratar a questão das favelas como problema social, apesar de continuar a removê-las e tentar acabar com elas. Em Belo Horizonte, foi criado o Departamento Municipal de Habitação e Bairros Populares (DBP), que tinha como função construir habitações para famílias retiradas de favelas. Essa mudança na forma de atuação do poder público estava fortemente relacionada com a atuação intensa dos movimentos populares em Belo Horizonte naquele período, marcada pelas várias ocupações de terrenos particulares e pela criação de várias organizações, como as Associações de Defesa Coletiva (ADC) e a Federação dos Trabalhadores Favelados de Belo Horizonte, criadas em 1955. As ADC foram um importante instrumento para reivindicação de direitos e para resistência a remoções de favelas, que, como outras organizações faveladas da época, contou com o apoio da ala progressista da Igreja Católica (AFONSO, 1988). É nesse contexto que se realiza, no ano de 1963, o Primeiro Seminário Nacional de Habitação e Reforma Urbana, que culminou na proposta do Governo do Estado de Minas Gerais de, pela primeira vez, construir conjuntos habitacionais para as populações das favelas e urbanizar algumas vilas e favelas.

Em 1964, com o Golpe Militar, as ações públicas voltadas para as vilas e favelas são sufocadas e os movimentos sociais e associações são reprimidos, lançados na ilegalidade e impedidos de atuar. Os favelados, bem como suas ocupações e associações, passam a ser tratados novamente como problema de polícia. Assim, em 1971, no auge da repressão militar, é criada a Coordenação de Habitação de Interesse Social (CHISBEL), órgão que realizou, entre 1971 e 1983, intervenções em 423 áreas da capital, removendo 10 mil barracos e 44 mil pessoas (GUIMARÃES, 1992).

A partir de 1975, sobretudo por intermédio da Pastoral das Favelas da Igreja Católica, as entidades faveladas começaram a se reestruturar e se reorganizar. A rearticulação dos movimentos sociais, somada às catástrofes causadas pelas chuvas de 1979 e 1982, levou o poder público estadual a modificar a forma de atuação em vilas e favelas. Em 1979, foi criado o Programa de Desenvolvimento de Comunidades 
(PRODECOM), da Secretaria de Estado de Planejamento e Coordenação Geral, que, em parceria com a CHISBEL e o PLAMBEL, ${ }^{3}$ realizou intervenções em 11 áreas de favelas, priorizando a participação dos moradores, por meio de mutirões, na fase do planejamento e da execução, atingindo 70 mil pessoas. Apesar de reconhecer o direito da população favelada a permanecer nessas áreas, o programa não realizou a legalização e titulação das áreas ocupadas.

Uma grande vitória dos movimentos sociais de Belo Horizonte ligados à luta pela moradia e pela melhoria das condições nas favelas foi a aprovação da Lei $\mathrm{n}^{\circ} 3.532$, de 6 de janeiro de 1983, que criou o Programa Municipal de Regularização de Favelas (PRO-FAVELA). A lei do PRO-FAVELA, ao reconhecer o direito dos favelados de terem a propriedade de suas moradias, representou uma grande vitória. Mas, apesar de ter sido criado em 1983, ele só foi regulamentado um ano depois, após muita pressão dos movimentos sociais e da Pastoral das Favelas, pela da lei 4.762, de 10 de agosto de 1984. Para implementar o PRO-FAVELA, a Prefeitura criou a Companhia Urbanizadora de Belo Horizonte (URBEL), que seria, a partir de então, o principal órgão para efetivação do programa; e, posteriormente, passa a ser o órgão responsável pela política urbana em vilas e favelas do município de Belo Horizonte.

Nesse momento de reafirmação e conquistas dos movimentos sociais em Belo Horizonte - que coincide com o processo de mobilização da Assembléia Nacional Constituinte de 1988 - é extinta a CHISBEL (marco da concepção de desfavelização), sendo criada a Secretaria Municipal de Ação Comunitária. Outro passo importante para os movimentos favelados foi a criação da Federação de Moradores de Bairros, Vilas e Favelas de Belo Horizonte (FAMOBH), que tinha como objetivo principal congregar as associações de moradores, na tentativa de unificar suas lutas (SOMARRIBA, 1984).

\section{Década de 1990: início do atual modelo de gestão das vilas e favelas da cidade}

É no bojo do momento político da Constituinte (final da década de 1980), da aprovação da Lei Orgânica do Município de Belo Horizonte em 1990 e das administrações progressistas pós-88, que a coligação Frente BH Popular, encabeçada pelo PT, vence as eleições municipais de 1992 e assume a Prefeitura de Belo Horizonte. As propostas dessa gestão são marcadas pela participação popular na construção do

\footnotetext{
${ }^{3}$ O Planejamento da Região Metropolitana de Belo Horizonte (PLAMBEL) foi um órgão do Governo do Estado de Minas Gerais, criado em 1974 para realizar estudos técnicos voltados para o planejamento da Região Metropolitana de Belo Horizonte, sendo extinto em 1996.
} 
programa de governo, que tem como uma das questões centrais a habitação, abrangendo as questões do déficit habitacional, dos sem casa e das vilas e favelas.

As duas principais e mais importantes marcas da Política Municipal de Habitação foram a concepção que insere a moradia num contexto mais amplo de direito à cidade e a preocupação com um planejamento integrado no qual as ações e intervenções não fossem mais pontuais, numa tentativa de otimizar e não desperdiçar recursos e ações do poder público (BEDÊ, 2005). A gestão do PT na Prefeitura de Belo Horizonte inaugurou, então, uma maneira de intervir nas vilas e favelas da cidade que vigora até hoje. A ideia e a crença em um planejamento articulado e global (MARICATO, 1997) nortearão as ações do executivo municipal durante toda a década de 1990 - sobretudo por intermédio da URBEL. Uma das principais características do planejamento inaugurado (utilizado e aprimorado até os dias de hoje) é o seu enfoque holístico, a confiança depositada na técnica e a centralidade da figura do Estado no planejamento, por meio de seus próprios técnicos e consultores terceirizados. A esse planejamento, que é uma herança do positivismo, Maricato (2000) chamou de modernista.

Um marco importante na política urbana de Belo Horizonte foi a aprovação do Plano Diretor (Lei $n^{\circ} 7125$, de 27 de agosto de 1996) e da Lei de Parcelamento, Ocupação e Uso do Solo Urbano (Lei n ${ }^{\circ}$ 7166, de 27 de agosto de 1996). No mesmo ano em que o Plano Diretor foi instituído, é sancionada a Lei de Parcelamento, Uso e Ocupação do Solo Urbano de Belo Horizonte, que "estabelece as normas e as condições para parcelamento, ocupação e uso do solo urbano no município" (BELO HORIZONTE, 1996), definindo parâmetros, requisitos e normas técnicas para loteamentos e construção de edificações (comerciais, industriais e habitacionais).

Um dos pontos essenciais dessa Lei para a definição das intervenções e formas de utilização do espaço urbano é o zoneamento de Belo Horizonte, que consiste na divisão da cidade em zonas com características físicas, ambientais e sociais semelhantes, buscando definir a "vocação" dos diferentes espaços para os diferentes fins. A classificação dos espaços da cidade limita e/ou determina as possibilidades de utilização deles. É importante perceber que os critérios para a classificação de uma área ou região em uma zona são, basicamente, as características físicas naturais, de infraestrutura e de modo de ocupação. A partir dessa classificação, são criados públicosalvo relacionados a cada zona, que deverão "receber" determinadas políticas e intervenções que visam determinado fim. 
Numa retomada histórica, é importante lembrar que as primeiras legislações municipais que criaram áreas ou zonas de interesse especial datam da década de 1980. $\mathrm{O}$ objetivo era flexibilizar e criar formas alternativas às leis de parcelamento do solo vigentes para os assentamentos "normais" e regulares, com vistas a atender às especificidades de assentamentos como vilas e favelas. Em Belo Horizonte, cidade pioneira (ao lado de Recife) na criação de uma legislação específica para vilas e favelas, o PRO-FAVELA, de 1983, representou uma vitória para os movimentos que lutavam por moradia e pela reforma urbana. Esse programa reconheceu o direito de permanência dos moradores em áreas ocupadas e previu a definição de critérios urbanísticos específicos para cada assentamento precário e informal, por intermédio da criação do Setor Especial-4 (SE-4), que definia as áreas de vilas e favelas. Assim, a delimitação das Zonas Especiais de Interesse Social (ZEIS), feita pelo zoneamento da cidade pela Lei de Parcelamento, Uso e Ocupação do Solo, em 1996, veio especificar e delimitar as áreas que poderiam ser urbanizadas, a partir de critérios específicos; transformou em ZEIS as áreas que haviam sido classificadas anteriormente como SE-4.

Se, por um lado, a reivindicação dos movimentos sociais por parâmetros específicos de urbanização de vilas e favelas visava a ampliar e criar instrumentos para exigir do poder público melhores condições nessas áreas, é interessante, por outro, pensar as ZEIS (bem como as SE-4 da década de 1980) como um mecanismo de controle dos espaços da cidade e de distinção entre eles; um mecanismo que identifica e marca os espaços e as populações que os ocupam, definindo tipos específicos de políticas para cada um deles. Além disso, a proposta é questionável, pois mesmo que a criação da ZEIS preveja a flexibilização dos parâmetros urbanísticos, a revisão da Lei $n^{\circ}$ 71666/96, em 2000, estabeleceu critérios específicos para o parcelamento, uso e ocupação do solo dessas zonas que guardam fortes semelhanças com as normas que vigoram para a cidade formal. Em outras palavras, foi utilizada a mesma lógica que rege a organização do espaço da cidade "formal", apenas adaptada para garantir que as populações e os espaços das vilas e favelas fossem controlados, geridos e organizados, na tentativa de modificá-los para que se assemelhassem cada vez mais aos da cidade "normal" ou "formal". Conforme Lefebvre (1999), a práxis dominante sempre tenta capturar os espaços diferenciais produzidos, como aqueles dos subúrbios.

Para implementar essa perspectiva de planejamento, a partir de 1997, a Prefeitura de Belo Horizonte institui o PGE como instrumento de política pública para as , tornando-o uma exigência "para aprovação de intervenções financiadas com 
recursos do OP." (PEREIRA, 2007). O PGE é uma espécie de plano diretor de cada vila ou favela que aborda os aspectos jurídico-legal, sócio-organizativo e físico-ambiental, procurando realizar um diagnóstico integrado, bem como construir uma escala de prioridades entre as intervenções levantadas. Seu principal objetivo é elaborar um diagnóstico integrado de cada ZEIS, criando "uma base de informações e de referência no contexto de uma política de investimentos progressivos, visando a consolidação dos assentamentos e a superação das fases de intervenção pontuais e desarticuladas." (PEREIRA, 2007).

Isso significa que todas as comunidades situadas em ZEIS só podem reivindicar recursos e obras se tiverem um PGE referente à sua vila ou favela, ou seja, essa exigência condicionou as intervenções e reivindicações dos locais a um estudo técnico, holístico e que pretende dar conta de todas as necessidades de um determinado local, além de garantir que em todas elas sejam seguidos os mesmos critérios para levantamento de dados e proposição de intervenções. Assim, a Prefeitura de Belo Horizonte, por intermédio do zoneamento e do PGE, implanta um tipo de intervenção que viabiliza, nas ZEIS, a concretização do espaço abstrato/planejado em detrimento do espaço vivido (LEFEBVRE, 2000). Ao colocar um plano, um planejamento como condição para a realização de melhorias e garantia de infraestrutura básica, o poder público exclui das suas possibilidades de ação o atendimento às demandas que surgem cotidianamente.

Mesmo após mais de 10 anos de instituição do PGE como condição para a realização de intervenções nas vilas e favelas, há comunidades que ainda não o concluíram, o que significa que, nesses locais, não houve intervenções estruturais, mesmo com a necessidade de certas obras. Portanto, o poder municipal criou uma condição para a realização de intervenções, mas transferiu para cada comunidade local a obrigação e a responsabilidade de obter recursos para a produção do PGE, um documento extenso, técnico e complexo, que, por essas características, exige um tempo grande, contratação de técnicos e uma quantia elevada de recursos para ser elaborado. Com a obrigatoriedade do PGE para cada vila e favela, a Prefeitura "força" as comunidades a decidirem pela aplicação de recursos do OP na elaboração do Plano, garantindo, dessa forma, que todas as vilas e favelas serão diagnosticadas e planejadas a partir dos mesmos critérios, sem que isso implique em um investimento maior.

Além da dificuldade para elaboração do PGE e da padronização que ele impõe, cabe mencionar outros problemas relativos aos critérios para sua elaboração. O primeiro 
refere-se à participação restrita da comunidade na elaboração, que se restringe à participação de um Grupo de Referência (GR), composto, basicamente, pelas lideranças locais, formais e informais; o pressuposto aceito é que há um grupo mais apto e preparado para fornecer e obter informações. ${ }^{4}$ Outro problema do PGE é que a linguagem utilizada privilegia a utilização de termos e conhecimentos técnicos e específicos; a linguagem técnica, além de ser um obstáculo à compreensão daqueles que não a dominam, é uma limitação simbólica, pois o formato técnico desqualifica e deslegitima outros projetos, visões e formas de expressá-los (ZHOURI, 2008). Um terceiro problema consiste na determinação dos aspectos a serem considerados na elaboração do PGE, pois, ao determinar o que deve ser diagnosticado, o poder público define um recorte que prioriza determinados aspectos em detrimento de outras demandas. O grande espaço de tempo entre as fases da obtenção de recursos no OP, levantamento, conclusão dos estudos e realização das obras também se constitui como um problema; no momento da realização das obras previstas pelo PGE, há um desencontro entre o projeto - baseado na realidade de um momento específico - e a realidade de fato, que é transformada e construída diária e cotidianamente. Outro problema é a fragmentação dos estudos e das propostas de intervenção, tanto no que refere aos eixos (físico-ambiental, sócio-organizativo e jurídico-fundiário) quanto às etapas para apresentação dos estudos; o fato de que a construção daquele espaço é resultado do entrelaçamento e da interdependência dos vários aspectos é ignorado.

Assim, o PGE tem como objetivo principal ser um instrumento para o poder municipal efetivar as políticas públicas pensadas pelos urbanistas e não algo a ser apropriados pelas comunidades locais. É nesse sentido que Lefebvre (1999; 2000) distingue urbanismo de urbano, quando afirma que o urbanismo é uma representação do urbano e oculta a verdadeira lógica urbana; é a pretensão do Estado de concretizar o espaço abstrato - aquele dos mapas, planos e projetos, uma abstração do que é vivido no cotidiano. Esse urbanismo carrega as marcas da era industrial, uma vez que pretende planificar e uniformizar o espaço, procurando subsumir outros projetos para o urbano e impedir a emergência de outras centralidades, característica essencial do urbano.

\footnotetext{
${ }^{4}$ As características do processo de elaboração do PGE (como também no processo do OP), no que se refere à participação das comunidades, estão inseridas em um contexto mais amplo, do início da década de 1990, em que a ideia de governança ganha destaque e passa a ser uma exigência de agências internacionais como o BID e o FMI. De acordo com Zhouri (2008), governança remete à ideia de gestão, realizada a partir de um consenso que abstrai a dimensão das relações de poder presentes nos processos sociais.
} 
Ademais, a conclusão do PGE não implica, necessariamente, a realização das obras e intervenções previstas. Assim, a origem do Programa Vila Viva está diretamente relacionada à estratégia de captação de recursos junto a agências financiadoras - como a Caixa Econômica Federal, o BID, BNDES ${ }^{5}$ - para execução das obras previstas nos PGE. Sendo o Vila Viva um programa para implementação das propostas dos PGE (obrigatórios para todas as vilas e favelas), esses dois elementos parecem compor um mecanismo que constrói a ideia da necessidade de se planejar a cidade dentro de uma concepção de planejamento e de urbanismo calcada no conhecimento técnico-científico, independente das discussões políticas e sociais que perpassam os problemas urbanos.

O Programa Vila Viva, elaborado pela Prefeitura Municipal de Belo Horizonte, por intermédio da URBEL, é vinculado à Política Municipal de Habitação e consiste em um conjunto de ações integradas, direcionadas à urbanização, ao desenvolvimento social e à regularização fundiária em vila e favelas de Belo Horizonte, além de procurar integrar outras políticas públicas para essa parcela da população. As intervenções em vilas e favelas de Belo Horizonte, no âmbito do Vila Viva, se iniciaram em 2004, no Aglomerado da Serra, região centro-sul - a região mais nobre da cidade. De acordo com informações do portal eletrônico da Prefeitura de Belo Horizonte, ${ }^{6}$ estão em curso intervenções nos aglomerados da Serra e Morro das Pedras, assim como nas vilas Califórnia, São José, Pedreira Prado Lopes e Taquaril.

Os critérios utilizados pela URBEL para a escolha das vilas e favelas que receberam as obras do Vila Viva não são claros. Ao contrário do que se poderia supor, os primeiros locais a receberem o Vila Viva são aquelas favelas que, em comparação com outras, possuem uma melhor situação com relação ao acesso a equipamentos sociais (saneamento, creches, escolas, postos de saúde etc.). Movimentos sociais denunciam que os critérios para a escolha das vilas e favelas são definidos pelo interesse do capital imobiliário, que tem como preferência as regiões mais próximas do centro da cidade $^{7}$. Assim, o objetivo seria melhorar determinadas áreas da cidade, modificando a paisagem da favela, os padrões urbanísticos e, principalmente, o sistema viário para

\footnotetext{
${ }^{5}$ Além de estabelecerem critérios e metas, esses órgãos financiadores operam numa lógica que privilegia os resultados, sobretudo quantitativos. Essas agências estipulam prazos para a conclusão das ações que apoiam, o que também é uma maneira de limitar as ações e induzir ao cumprimento das metas, mesmo que isso comprometa a qualidade. Assim, as chances da comunidade interferir para modificar ou ao menos ajustar/adaptar os projetos e planos ficam ainda mais reduzidas.

${ }^{6}$ Disponível em: <www.pbh.gov.br>. Acesso em: 04 abr. 2012.

${ }^{7}$ Ver, por exemplo, o Manifesto Vila Viva ou Vila Morta, disponível em: <http://prod.midiaindepende nte.org/pt/blue/2008/10/429697.shtml>.
} 
atender demandas da cidade formal, que pouco mudariam a vida das pessoas das vilas. Das seis primeiras áreas onde foram realizadas as primeiras obras do Vila Viva, em três serão abertas grandes vias para viabilizar o trânsito de regiões nobres e importantes da cidade.

Para a realização das obras, o Vila Viva prevê a desapropriação de casas e remoções de famílias, que ocorrem por dois motivos: retirada de área de risco geológico (deslizamento de terra, enchente, desabamento) ou retirada de trecho de obra, caso em que também estão inseridas as famílias vítimas de danos indiretos causados pelas obras (rachaduras, trincas, abalo de estrutura do imóvel etc.). Em ambos os casos, as áreas de remoção já estão definidas no PGE, sendo feitos ajustes e acertos no projeto executivo de cada área a receber intervenção. No que se refere à indenização, as opções dadas às famílias removidas são três: 1) indenização pelas benfeitorias realizadas na casa, que consiste na avaliação da qualidade dos materiais utilizados na construção, mas ignora a localização do terreno e o tamanho da casa, o que deixa o valor da indenização muito baixo; 2) compra de uma casa pela prefeitura no valor de até $\mathrm{R} \$ 30.000,00$ à escolha da família, o que implicaria na saída da favela para alguma área da região metropolitana afastada do centro, pois com esse valor não é possível comprar uma casa em Belo Horizonte; 3) um apartamento na favela de origem, construído no âmbito do Programa Vila Viva.

Apesar de existirem três opções para indenização, os critérios utilizados para estabelecê-las têm implicações que acabam por restringir a possibilidade de escolha dos moradores. O reassentamento autônomo (indenização em dinheiro), ao considerar só as benfeitorias, deixa as indenizações muito baixas. No reassentamento monitorado, o valor máximo ( $\mathrm{R} \$ 30.000,00)$ é muito baixo para adquirir uma casa, sobretudo em Belo Horizonte. Os apartamentos se tornam, então, a única chance de permanência no local, o que leva muitos moradores a escolher morar nos conjuntos construídos na própria favela. A realocação nos apartamentos - espaço distinto daquele das casas e barracos implica transformações e mudanças para esses novos moradores; apesar de terem permanecido no Aglomerado de origem, vivenciarão situações bastante novas, desconhecidas e diferentes das estratégias que criaram para sobreviver nesses locais: a laje, o pedaço (MAGNANI, 1984 apud CHAUÍ, 1984), as relações com os vizinhos, o comércio em conjunto com a casa etc. Essa situação leva à perda de referências culturais e simbólicas e das relações de vizinhança ligadas àquele espaço específico, coisas impossíveis de serem quantificadas e monetarizadas (ZHOURI; TEIXEIRA, 
2005). O depoimento de uma moradora revela a importância dessa relação com os vizinhos.

Em questão de vizinhança, eu preferia lá [casa de onde foi removida] mesmo. Até porque eu cresci com os meninos vizinhos, que acabou virando minha família, que os irmãos casaram com as minhas irmãs, minha irmã casou na outra casa. Então, em questão de amizade eu gostava mais de lá. (Moradora do Aglomerado da Serra há mais de 40 anos, removida para construção de uma Área de Proteção Ambiental e reassentada no apartamento).

Para os moradores que já tinham o desejo de morar em apartamento, a remoção não significou uma imposição. Mas, e aqueles que queriam permanecer no aglomerado, tinham indenizações baixas e não queriam morar em apartamentos? Nesse sentido, é importante perceber como, para além dos desejos de cada morador, foi criado um mecanismo para conduzir os moradores a optarem pelos apartamentos. A situação vivida por uma moradora do Aglomerado do Morro das Pedras, removida devido a danos causados por obras do próprio Programa à sua casa, elucida essa questão.

\begin{abstract}
Eles sempre oferecem, eles sempre oferecem para a pessoa (pelo menos é a gente fica sabendo) eles sempre oferecem a opção ou pegar o dinheiro ou ganhar o apartamento. No meu caso não, eles nem chegaram a oferecer o dinheiro nenhuma hora. [...] Eu já tinha preferência, mesmo se tivessem falado "você tem a opção [do dinheiro ou do apartamento]" Eu já preferia o apartamento, porque como o meu barraco era muito pequeno, o dinheiro que ele valia não dava para comprar uma casa. [...] Com certeza, porque a minha família está aqui, minha mãe mora aqui perto. Eu tinha que ficar aqui mesmo! (Moradora do Morro das Pedras há 23 anos, removida devido a danos causados por obra do Vila Viva à sua casa).
\end{abstract}

Uma moradora que foi removida do Aglomerado da Serra, tinha uma indenização muito baixa e queria permanecer no Aglomerado, afirmou:

Olha, nós já não queríamos, nós não queríamos vir pra cá [o apartamento] não, foi difícil, ninguém quis. Minha filha teve síndrome do pânico e ninguém quis ficar aqui não. A gente custou a acostumar aqui, porque a gente não conhecia ninguém. [...] Na casa que a gente morou lá em cima era mil vezes melhor, porque era bem mais espaçosa, terreiro e aquela coisa toda. Aqui, porque ... chegamos, não conhecia ninguém, a gente já não queria ficar aqui, a gente estava muito acostumado com a casa lá em cima, os meninos [os filhos] também. [...] Eles não queriam muito não, eles [os filhos crianças] choraram muito quando nós saímos da casa. Essa menina ali [uma das crianças de 5 anos] vivia pedindo pra gente voltar pra casinha dela. Até hoje a gente passa lá a gente vê o lugar onde foi a casa e ela fala "ali era onde eu morava, eu queria voltar pra minha casinha.", quer dizer, eles sentem muita falta. (Moradora do Aglomerado da Serra há mais de 30 anos, removida de área de risco e reassentada no apartamento). 
Essa situação evidencia a oposição entre o habitat e o habitar, como definidos por Lefebvre (1999). O habitat, fruto de um urbanismo nascido no século XIX, restringe o ser humano a alguns atos elementares como comer, dormir e reproduzir-se. "O habitat foi instaurado pelo alto: aplicação de um espaço global homogêneo e quantitativo obrigando o 'vivido' a encerrar-se em caixas, gaiolas, ou 'máquinas de habitar"” (p. 81). Ao contrário, o habitar está associado ao vivido, ao cotidiano, ao concreto, aos significados e sentimentos atribuídos ao espaço de moradia, para além do utilitarismo do habitat. Nesse sentido, a casa, a morada deve ser encarada não como um espaço para se dormir, comer e reproduzir, pois o ser humano tem, além de necessidades, desejos e projetos. Esses desejos e projetos geram contradições, fissuras e resistência, coisas das quais o urbanismo não dá conta, pois procura ignorá-las ou superá-las, por meio da homogeneização.

Ao criar mecanismos para que os moradores removidos escolham os apartamentos, o Estado, nesse caso representado pela Prefeitura, amplia sua capacidade de controlar a vida das pessoas. O pagamento de contas, o controle do crescimento da família imposto pela limitação do espaço e a falta de espaço para as crianças demonstram a impossibilidade de se reproduzir, ou mesmo repor, com um apartamento, uma casa da qual não se queria sair. Uma moradora relata as transformações na vida da família decorrentes da mudança para o apartamento.

Lá tinha liberdade total, brincava, tinha todos os amiguinhos, conhecia todo mundo, descia e subia o beco não tinha problema nenhum, ai eles acostumaram muito lá. Agora aqui [no apartamento] fica difícil porque eles ficam muito preso, porque não pode ficar lá embaixo (Moradora do Aglomerado da Serra há mais de 30 anos, removida de área de risco e reassentada no apartamento).

E sobre as contas, acrescenta:

Quando eu morava em casa eu não tinha tanta conta pra pagar como agora, é muita conta. Pra você ter ideia, quando você tá morando numa casa, você só paga sua luz e sua água, quando você está morando no apartamento, você tem que pagar condomínio, luz, água e alguns gastos a mais que acontece no prédio (Moradora do Aglomerado da Serra há mais de 30 anos, removida de área de risco e reassentada no apartamento).

Parece que a pretensão é realizar um projeto civilizatório (REBOUÇAS, 2000) que tem como referência, para a produção dos novos espaços de reassentamento, o modelo urbano da cidade formal em detrimento da organização do espaço produzida na favela. Como afirma Rebouças (2000), persiste a ideia de que a produção de novos 
espaços com referência em outros padrões possa transformar e melhorar as relações sociais e o padrão de vida da população reassentada.

A visão da Prefeitura, da URBEL e dos técnicos sociais, expressa nas reuniões do Projeto Pré-Morar ${ }^{8}$ com os moradores, nas conversas informais e nos jornais de divulgação das obras, é de que os apartamentos são a melhor opção de reassentamento. Um dos técnicos sociais afirmou que os apartamentos significarão um salto na qualidade de vida dos moradores, tendo em vista a qualidade das casas em que moravam; que os moradores, devido ao apego à casa de origem, podem até não perceber isso em um primeiro momento, mas que, no futuro, eles verão. Por isso, todo o trabalho dos técnicos sociais está pautado nessa certeza, a partir da qual tentam, de acordo com seus próprios termos, fazer um trabalho de convencimento do morador para conscientizá-lo das vantagens de morar no apartamento, que podem não estar claras devido ao apego à casa de origem, ao modo de vida em casa ou até por falta de instrução. A ideia que os técnicos têm dos moradores da favela reflete a crença de que eles necessitam de informações e de figuras técnicas para orientá-los quanto à melhor escolha a fazer, quanto à melhor forma de morar, quanto ao que será melhor para o aglomerado. Dessa forma, torna-se possível designar os moradores removidos como beneficiários, desqualificando o modo e a condição de vida em barracos e casas.

Nesse sentido, as ações do Pré-Morar são emblemáticas no que se refere ao acionamento do discurso técnico para justificar posições, decisões e percepções, principalmente nos momentos de questionamentos, conflitos e problemas com os moradores. Nessa tentativa de conferir neutralidade às suas ações e legitimá-las, as práticas culturais são contrapostas ao discurso técnico, sendo, geralmente, classificadas como irracionais, ignorantes, sem que seja assumida a conotação moral que perpassa esse discurso técnico (SIENA, 2010). A lógica pela qual os técnicos operam "superficializa e esvazia as práticas sociais, destituindo-as de seu sentido" (VARGAS, 2006, p. 29); eles associam, àqueles moradores que não compartilham de suas visões, imagens de carência de informação e, sobretudo, de formação, tentando, dessa forma, anular as formas autônomas de agir e pensar.

\footnotetext{
${ }^{8}$ Acompanhei durante 3 meses reuniões do Projeto Pré-Morar no Aglomerado do Morro das Pedras. O Projeto Pré-Morar tem o objetivo de "preparar as famílias que serão reassentadas nos apartamentos, com o objetivo de informar, integrar, discutir e planejar a forma de ocupação do condomínio, garantindo o seu uso adequado, sua manutenção e conservação.” (ASSESSORIA SOCIAL E PESQUISA, 2008b, p. 1).
} 


\section{Considerações finais}

Alijados, desde o processo de construção e urbanização de Belo Horizonte, dos benefícios e direitos, os moradores de vilas e favelas criaram estratégias específicas para sobreviver nesses locais: a laje, o pedaço (MAGNANI, 1984 apud CHAUÍ, 1984), as relações com os vizinhos, o comércio em conjunto com a casa etc., construindo suas vidas em estreita relação com o espaço em que vivem. Ao mesmo tempo em que construíam suas vidas, realizavam lutas reivindicatórias frente ao poder público para garantir direitos e condições dignas de vida nas favelas. Isso não significa dizer que a população favelada, dotada de grande criatividade, não necessita que o poder público atenda às suas reivindicações e solucione os problemas e carências nas favelas; ao contrário, o que é preciso ressaltar nas lutas (seja pela sobrevivência, seja pela garantia de direitos) é a forma específica como cada comunidade as conduziu, assim como as principais necessidades apontadas por quem vive nesses locais.

Tendo em vista tais especificidades, a falta de infraestrutura e a luta para conquistá-las não são, automaticamente, justificativas e legitimação para a implementação de qualquer programa ou projeto de intervenção em vilas e favelas, ou seja, não significa que o Estado possa impor modelos de bairros, de ruas, de casas. Diferentemente, as reivindicações dos movimentos favelados, ao longo da história de Belo Horizonte, ressaltam as particularidades de se viver em favela: as relações criadas, a relação específica com o espaço e a necessidade de as políticas públicas as respeitarem e as considerarem no momento de realizar obras e remoções. Porém, isso não ocorre com o Vila Viva, que é um Programa para ser aplicado em todas as Vilas e Favelas, a partir de dados do PGE, um documento que tem a mesma metodologia e os mesmos quesitos para serem seguidos em todas as vilas e favelas.

O Estado, depois de anos de ausência, diz aos moradores que a forma como eles vivem não é a melhor nem a mais adequada, atribuindo essa "falha" à falta de formação e conhecimento dos próprios moradores. Essa lógica define os moradores e suas escolhas pela negatividade (ausência, carência, falta) e nunca pela sua positividade (outras formas de ver o mesmo espaço, outros projetos, outras concepções), ignorando que a relação com o espaço diz de uma leitura e de uma relação com o mundo (REBOUÇAS, 2000) que, entre os diferentes sujeitos, são diferentes e até excludentes. Podemos pensar, então, que a Prefeitura Municipal de Belo Horizonte, muito mais do que atender às reivindicações, se apropria dos discursos dos movimentos sociais para 
legitimar as intervenções do Vila Viva. Essa apropriação transforma os moradores de vilas e favelas em carentes e necessitados, transforma direitos em benefícios, transforma terrenos íngremes em áreas de risco, transforma casas pequenas em barracos insalubres e, acima de tudo, transforma histórias de vida em obstáculo à "melhoria" da qualidade de vida.

Com tais críticas não pretendo dizer que não há problemas e ausência de investimentos do poder público nas vilas e favelas, pois isso seria romantizar a pobreza e as dificuldades vividas cotidianamente pelos moradores desses locais. Todavia, a utilização que o poder público faz desse fato, ao construir tal imagem da favela, legítima e justifica um urbanismo que disciplina, normatiza e regulamenta as cidades (PECHMAN, 2002) e as pessoas que nela vivem. E essa lógica se aplica, sobretudo, às vilas e favelas.

Para pensar possibilidades de intervenções em vilas e favelas se torna essencial, portanto, considerar e compreender a existência de relações sociais e afetivas que estão diretamente relacionadas com o lugar onde se vive e que estão expressas e marcadas na casa, no terreiro, na rua, na vizinhança, na venda. Considerar tudo isso implica reconhecer a possibilidade de um projeto de cidade que, como já dito, não pretenda concretizar o espaço planejado/abstrato em detrimento do espaço vivido - aquele criado e recriado cotidianamente (LEFEBVRE, 2000). Conferir importância ao vivido implica, sobretudo, reconhecer que a principal característica do urbano é a diferença, a diversidade, a fissura, a tensão, ou seja, a existência na cidade de diferentes formas de produzir, significar e viver no espaço (LEFEBVRE, 1999; 2000). 


\title{
From the construction of the new capital of the Minas Gerais state to the current model of management of villages and slums: notes on a case study of the Vila Viva Program
}

\begin{abstract}
Belo Horizonte was designed to be a model of cleanliness and progress. However, due to its exclusionary design project, the city had to deal with the issue of slums even before its inauguration. From the 1990s the local government has been applying a conception of urban planning based on a technical discourse that has led to the program called Vila Viva (village alive), a program of intervention in the slums. In order to legitimize these public interventions, residents are defined by negativity and their ways of relating to the space are ignored. Thus, the program reveals the government's pretension to control and homogenize the slums' space and population.
\end{abstract}

Key words: Urban planning; Public policies towards slums; Slums; Vila Viva program.

\section{Referências}

AFONSO, Mariza Rezende; AZEVEDO, Sérgio de. Poder público e movimento de favelados. In: POMPERMAYER, Maiori (Org.). Movimentos Sociais em Minas Gerais: emergência e perspectivas. Belo Horizonte: UFMG, 1988.

ASSESSORIA SOCIAL E PESQUISA. Projeto de trabalho técnico social do Aglomerado do Morro das Pedras. 2008a.

ASPAssessoria Social e Pesquisa. Projeto Pré-Morar do Aglomerado do Morro das Pedras. 2008b.

BEDÊ, Mônica. Trajetória da Formulação e Implantação da Política Habitacional de Belo Horizonte na Gestão da Frente BH Popular: 1993-1996, 2005. [302]f. Dissertação (Mestrado em Geografia) - Instituto de Geociências da Universidade Federal de Minas Gerais, Belo Horizonte.

BELO HORIZONTE. Lei $\mathrm{n}^{\mathrm{o}} 7.165$ de 27 de agosto de 1996. Institui o Plano diretor do Município de Belo Horizonte. Disponível em: <http://bhz5.pbh.gov.br/legislacao.nsf/42 d34f6e3014477e0325679f0041f8fa/cd8446d8f87886040325679a0057652c?OpenDocu ment>. Acesso em: 04 abr. 2012. 
BELO HORIZONTE. Lei $\mathrm{n}^{\circ} 7.165$ de 27 de agosto de 1996. Estabelece normas e condições para parcelamento, ocupação e uso do solo urbano no município. Disponível em: 〈http://www.pbh.gov.br/mapas/leiuso/lei-7166.htm>. Acesso em: 04 abr. 2012.

BRANDENBERGER, Francys. Plano global específico: um instrumento de planejamento urbano em assentamentos subnormais. In: ZENHA, Rosimari; FREITAS, Carlos Geraldo Luz de (Org.). Anais do Seminário de avaliação de projetos IPT em habitação e meio ambiente: assentamentos urbanos precários. São Paulo: Coleção Habitare. 2002.

BURGOS, Marcelo B. Dos parques proletários ao favela-bairro - as políticas públicas nas favelas do Rio de Janeiro. In: ZALUAR, Alba; ALVITO, Marcos (Org.). Um Século de Favela. Rio de Janeiro: Editora Fundação Getúlio Vargas, 1998.

CHAUI, Marilena de Souza. Conformismo e resistência: aspectos da cultura popular no Brasil. São Paulo: Brasiliense, 1986.

COSTA, Heloísa. Habitação e produção do espaço em Belo Horizonte. In: MONTEMOR, R. (Org.) Belo Horizonte: espaços e tempos em construção. Belo Horizonte: CEDEPLAR, 1994.

GUIMARAES, Berenice Martins. Favelas em Belo Horizonte: tendências e desafios. Análise e onjuntura, Belo Horizonte, v. 7, n. 2;3, p. 11-18, maio/dez. 1992.

FICHEIRO: Planta BH. Wikipédia. Disponível em: <http://pt.wikipedia.org/wiki/Ficheiro:Planta_BH.jpg>. Acesso em: 16 abr. 2012.

GUIMARAES, Berenice. Minas Gerais: a construção da nova capital. Análise e Conjuntura, Belo Horizonte, v. 8, n. 2;3, p. 17-31, maio/dez. 1993.

LEFEBVRE, Henri. A Revolução Urbana. Belo Horizonte: Editora UFMG, 1999.

LEFEBVRE, Henri. La Production de L'espace. 4. ed. Paris: Anthropos, 2000.

LE VEN, Michel M. Classes Sociais e Poder Político na Formação Espacial de Belo Horizonte (1893-1914). 1977. 174 f. Dissertação (Mestrado em Ciência Política) Faculdade de Filosofia e Ciências Humanas da Universidade Federal de Minas Gerais, Belo Horizonte.

MARICATO, Ermínia. Brasil 2000: qual planejamento urbano? Cadernos IPPUR, Rio de Janeiro, Ano XI, n. 1/2, p. 113-130, 1997.

MOTTA, Luana D. A normatização da limpeza e da beleza no Aglomerado do Morro das Pedras-BH: estratégias legais, políticas e discursivas para implementação do Programa Vila Viva. 2009. 76 f. Monografia (Graduação em Ciências Sociais) Faculdade de Filosofia e Ciências Humanas da Universidade Federal de Minas Gerais, Belo Horizonte.

PECHMAN, R. M. Cidades estreitamente vigiadas: o detetive e o urbanista. Rio de Janeiro: Casa da Palavra, 2002. 
PEREIRA, Claudius Vinícius Leite; AFONSO, Andrea Scalon; MAGALHÃES, Maria Cristina Fonseca de. Programa Vila Viva: Intervenção estrutural em assentamentos precários. Apresentado no $17^{\circ}$ Encontro Nacional da Anamma, Recife, 2007. Disponível em: <http://portalpbh.pbh.gov.br/pbh/ecp/contents.do?evento=conteudo\&id Conteudo=22546\&chPlc=22546\&viewbusca=s $>$. Acesso em: 16 out. 2012.

REBOUÇAS, Lidia Marcelino. O Planejado e o Vivido: o reassentamento de famílias ribeirinhas no Pontal do Paranapanema. São Paulo: AnnaBlume/FAPESP, 2000.

ROSA, Susel Oliveira. Da violência, da Pureza e da Ordem. Revista Urutágua revista acadêmica multidisciplinar, Maringá, n. 9, abr./jul. 2006.

SIENA, Mariana. Remoção de Famílias das Áreas Consideradas de Risco: a técnica de fazer viver e deixar morrer. Trabalho apresentado na $34^{\circ}$ Encontro Anual da Anpocs, Caxambu, 2010. Disponível em: <http://www.ufscar.br/neped/pdfs/anais/ANPOCS2010_

Mariana_Siena.pdf $>$. Acesso em: 04 maio 2011.

SOMARRIBA, Maria das Mercês Gomes; VALADARES, Maria Gezica; AFONSO, Mariza Rezende; Fundação João Pinheiro. Lutas urbanas em Belo Horizonte. Petrópolis: Vozes, 1984.

VARGAS, Maria Auxiliadora R. Construção Social da Moradia de Risco: trajetórias de despossessão e resistência - a experiência de Juiz de Fora/MG. 2006. 160 f. Dissertação (Mestrado em Planejamento Urbano e Regional). Instituto de Pesquisa e Planejamento Urbano e Regional da Universidade Federal do Rio de Janeiro, Rio de Janeiro.

ZHOURI, Andréa. Justiça Ambiental, Diversidade Cultural e Accountability: desafios para a governança ambiental. Revista Brasileira de Ciências Sociais, v. 23, n. 68, p. 97-107, out. 2008.

ZHOURI, Andréa; TEIXEIRA, Raquel. O. S. Paisagens industriais e desterritorialização de populações locais: conflitos socioambientais em projetos hidrelétricos. In: ZHOURI, A.; SIANO, D. B. P.; LASCHEFSKI, K. (Org.). A insustentável leveza da política ambiental: desenvolvimento e conflitos socioambientais. Belo Horizonte: Autêntica, 2005. 